\title{
Round Ligament of the Uterus
}

National Cancer Institute

\section{Source}

National Cancer Institute. Round Ligament of the Uterus. NCI Thesaurus. Code C34009.

A fibrous band extending from the uterine horn to the labium majora via the inguinal canal that maintains the uterus in an anteverted position. 